\title{
Importance of The Medical History in The Diagnosis of Hypersensitivity Pneumonitis: A Case Report
}

Seval Müzeyyen Ecin ${ }^{1}$, [MD]

ORCID: 0000-0002-7701-7826

Abdulsamed Sandal ${ }^{2}$,[MD]

ORCID: 0000-0002-9718-7769

Adem Koyuncu ${ }^{3}$, [MD]

ORCID: 0000-0003-4834-1317

Şerife Gül Ö $z^{4},[M D]$

ORCID: 0000-0002-5197-445X

${ }^{1}$ Unit of Occupational Medicine, Mersin City Training and Research Hospital, Mersin, Turkey.

${ }^{2}$ Unit of Occupational Medicine, Ankara Occupational and Environmental Diseases Hospital , Ankara, Turkey.

${ }^{3}$ Unit of Occupational Medicine, Atatürk Chest Diseases and Chest Surgery Training and Research Hospital,

Ankara, Turkey.

${ }^{4}$ Hacettepe University, Faculty of Medicine, Depart-

ment of Internal Medicine, Unit of General Internal

Medicine, Ankara, Turkey.

\section{wee ABSTRACT Cen}

Hypersensitivity pneumonitis occurs in lungs as a result of type IV hypersensitivity reaction against various types of antigens sourced from animals, plants, fungi, bacteria, or low-molecular-weight chemical agents including isocyanates or metal fumes. Although more sophisticated tests may be required for definitive diagnosis, initial suspicion may develop only if the patient's medical history is detailed in terms of environmental or occupational exposures. Herein, we report a 32-year old male patient presented with dyspnea, dry cough, fatigue, and weight loss. Previous treatments for respiratory infections and asthma suggested by another center had failed. $\mathrm{He}$ was consulted to our occupational disease's unit for any possible occupational lung disease including pneumoconiosis, due to his employment in production of stainless-steel kitchen equipment. Detailed anamnesis revealed that the patient was also a pigeon breeder. Combining both detailed anamnesis of relevant exposures and supporting findings in high-resolution computed tomography of the chest and bronchoalveolar lavage cytology, the patient was diagnosed as hypersensitivity pneumonitis in collaboration with our hospital's multidisciplinary team for pulmonary diseases.

Key words: Hypersensitivity pneumonitis, extrinsic allergic alveolitis, interstitial lung diseases, medical anamnesis

Corresponding Author: Seval Müzeyyen Ecin.

Unit of Occupational Medicine, Mersin City Training and Research Hospital, Mersin, Turkey

e-mail: muzeyyenecin@hacettepe.edu.tr

Phone: 05059190591

Received: 16 July 2020, Accepted: 17 July 2020,

Published online: 30 September 2020

\section{INTRODUCTION}

Hypersensitivity pneumonitis (HP), formerly called extrinsic allergic alveolitis, occurs as a result of nonIgE related type IV (delayed-type) hypersensitivity reaction against various types of agents, namely antigens or chemicals, exposed environmentally or occupationally [1]. Diagnosis of HP is made by combining clinical features, physical examination, findings of laboratory, radiological and pathological tests. Those tests contain high-resolution computed tomography (HRCT) of the chest, precipitating antibodies in blood or bronchoalveolar lavage (BAL), BAL cytology, or lung biopsy [2]. Although 
additional tests are required for diagnosis, the suspicion for HP should develop initially when the medical history of the patient suggests a relevant exposure for HP in order to plan advanced tests. It may be difficult to obtain information about exposures, whether occupational or environmental, when the physician only focuses on the patient's symptoms, physical examination findings, and test results [3]. Such a situation may cause a delay for a correct diagnosis and appropriate management. Herein we present a case with HP in whom a diagnosis could be made in our hospital, after taking a detailed medical history of relevant exposures, whereas the patient had a long history of seeking medical care.

\section{CASE PRESENTATION}

A 32-year-old male non-smoker patient was consulted to our unit of occupational diseases with a suspicion of occupational lung disease including pneumoconiosis. His complaints at the time of application were shortness of breath, limitation of physical capacity, dry cough, and weight loss of 15 kilograms during last six months. The patient had defined an episode with flu-like symptoms at the beginning and been prescribed antibiotics for respiratory infection and inhaled treatments for asthma subsequently.

He had been working for approximately seven years in the production of kitchen equipment made from stainless steel by cutting, bending, cleaning with sandpaper and sponge, and welding (electrode arc welding and argon gas-shielded arc welding) of stainless-steel sheets in different small companies. He worked only on weekdays and his eight-hour daily shift. He declared that he was using protective eyeglasses, but not any respiratory protectors. No colleagues had similar symptoms. The patient defined an increase in his symptoms after starting work, particularly on Mondays. He told that his last periodical was performed two years ago with a chest $\mathrm{X}$-ray and audiogram with normal results.

He was questioned for his environmental exposures. It revealed that he bred up to ten pigeons at the basement of his house and up to fifteen pigeons at a place next to his workplace where he spent a substantial duration of time, especially on Mondays after the weekend and during workdays before starting work. When his symptoms initiated, a physician suggested to remove the pigeons from the house building, thus he tried to avoid long durations of feeding and cleaning when he was at home, but he continued those activities at the workplace. Patient's medical and family history was otherwise normal.

On physical examination, his general condition was fine, and he was fully conscious. The vital findings were within normal limits and there were not any abnormal findings in physical examination. Patient's laboratory and lung function test findings are given in Table 1. Spirometry revealed a restrictive pattern. His 6-minute-walking-test and carbon monoxide diffusion was normal. 
Table 1. Histological subtypes of patients

\begin{tabular}{|c|c|}
\hline Test & Result \\
\hline \multicolumn{2}{|l|}{ Blood Tests } \\
\hline Hemoglobin & $15.9 \mathrm{gr} / \mathrm{dl}$ \\
\hline White Blood Cells & $7.8 \times 103 / \mu \mathrm{L}$ \\
\hline Neutrophils & $4.7 \times 103 / \mu \mathrm{L}$ \\
\hline Eosinophils & $0.1 \times 103 / \mu \mathrm{L}$ \\
\hline Basophils & $0.1 \times 103 / \mu \mathrm{L}$ \\
\hline Lymphocytes & $2.2 \times 103 / \mu \mathrm{L}$ \\
\hline Platelets & $286 \times 103 / \mu \mathrm{L}$ \\
\hline Sodium & $135 \mathrm{mEq} / \mathrm{L}$ \\
\hline Potassium & $4.32 \mathrm{mEq} / \mathrm{L}$ \\
\hline Creatinine & $0.77 \mathrm{mg} / \mathrm{dL}$ \\
\hline ALT & $17 \mathrm{U} / \mathrm{L}$ \\
\hline AST & $18 \mathrm{U} / \mathrm{L}$ \\
\hline Total bilirubin & $0.66 \mathrm{mg} / \mathrm{dL}$ \\
\hline Direct bilirubin & $0.097 \mathrm{mg} / \mathrm{dL}$ \\
\hline Albumin & $3.84 \mathrm{~g} / \mathrm{dL}$ \\
\hline Total Protein & $7.53 \mathrm{~g} / \mathrm{dL}$ \\
\hline Lead & $4.83 \mu \mathrm{g} / \mathrm{dL}(0-5)$ \\
\hline Manganese & $18.9 \mu \mathrm{g} / \mathrm{L}(4.2-16.5)$ \\
\hline Cadmium & $3.3 \mu \mathrm{g} / \mathrm{L}(0-5)$ \\
\hline Mercury & $4.7 \mu \mathrm{g} / \mathrm{L}(0-10)$ \\
\hline Arsenic & $5.01 \mu \mathrm{g} / \mathrm{L}(0-12)$ \\
\hline Cobalt & $0 \mu \mathrm{g} / \mathrm{L}(0.5-3.9)$ \\
\hline QuantiFERON & Negative \\
\hline \multicolumn{2}{|l|}{ Pulmonary Function Tests } \\
\hline \multicolumn{2}{|l|}{ Spirometry } \\
\hline FVC & $3.22(67 \%)$ \\
\hline FEV1 & $2.81(70 \%)$ \\
\hline FEV1/FVC & $87 \%$ \\
\hline FEF25-75 & $4.11(88 \%)$ \\
\hline FEV1 after bronchodilator inhalation & $2.54(71 \%)$ \\
\hline Carbon monoxide diffusion & $112 \%$ \\
\hline 6-minute walking test & Normal \\
\hline
\end{tabular}

In his chest X-ray, bilateral increased reticular densities were observed (Figure 1). HRCT revealed radiological findings supporting subacute hypersensitivity pneumonitis such as bilateral diffuse millimetric centrilobular ground-glass nodules which are coalescing in some areas, mosaic perfusion and air trapping in basal areas (Figure 2). Abdominal CT was normal except mild hepatomegaly and splenomegaly. 


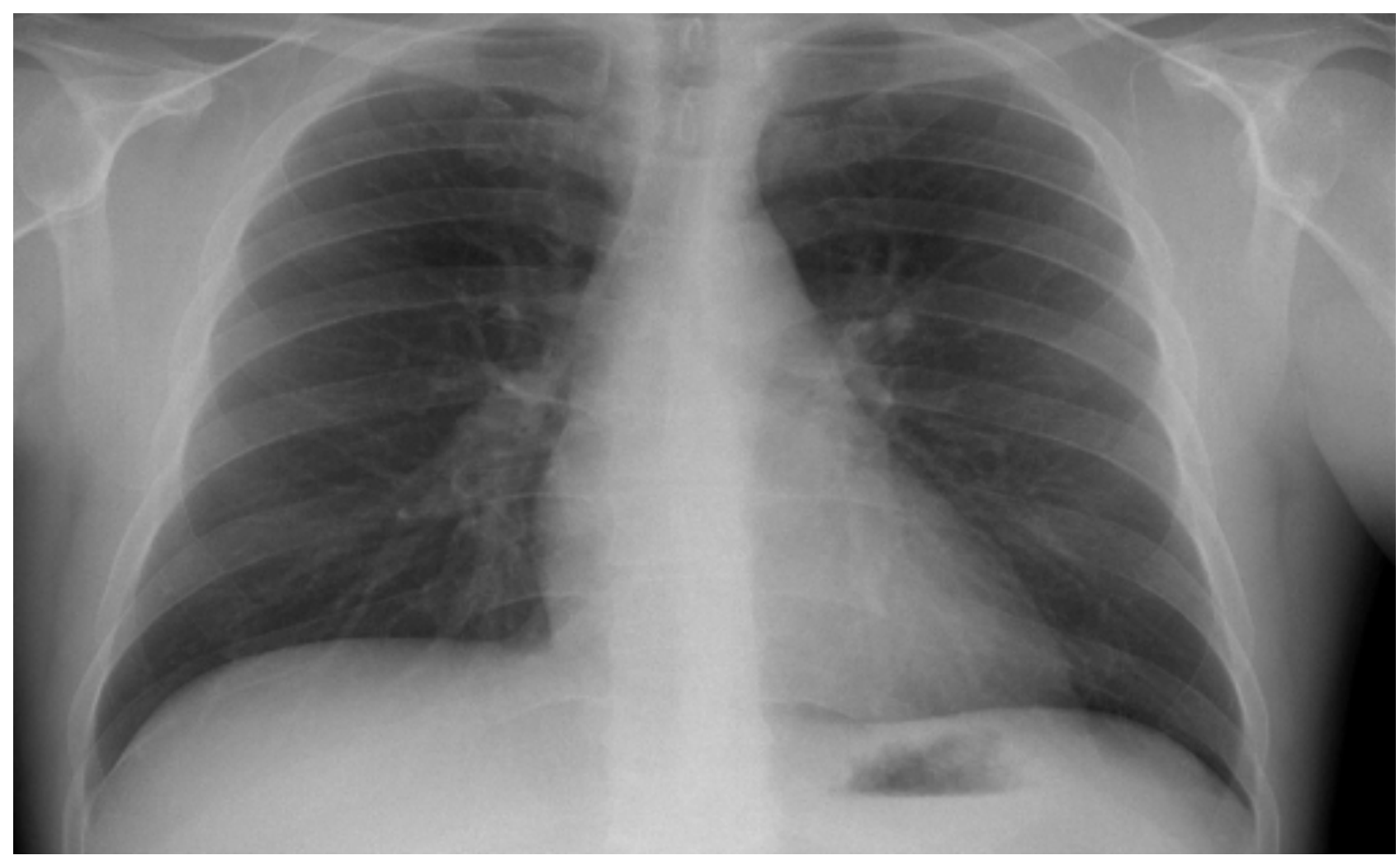

Figure 1. Patient's chest X-ray. Bilateral increase in reticular densities was observed.
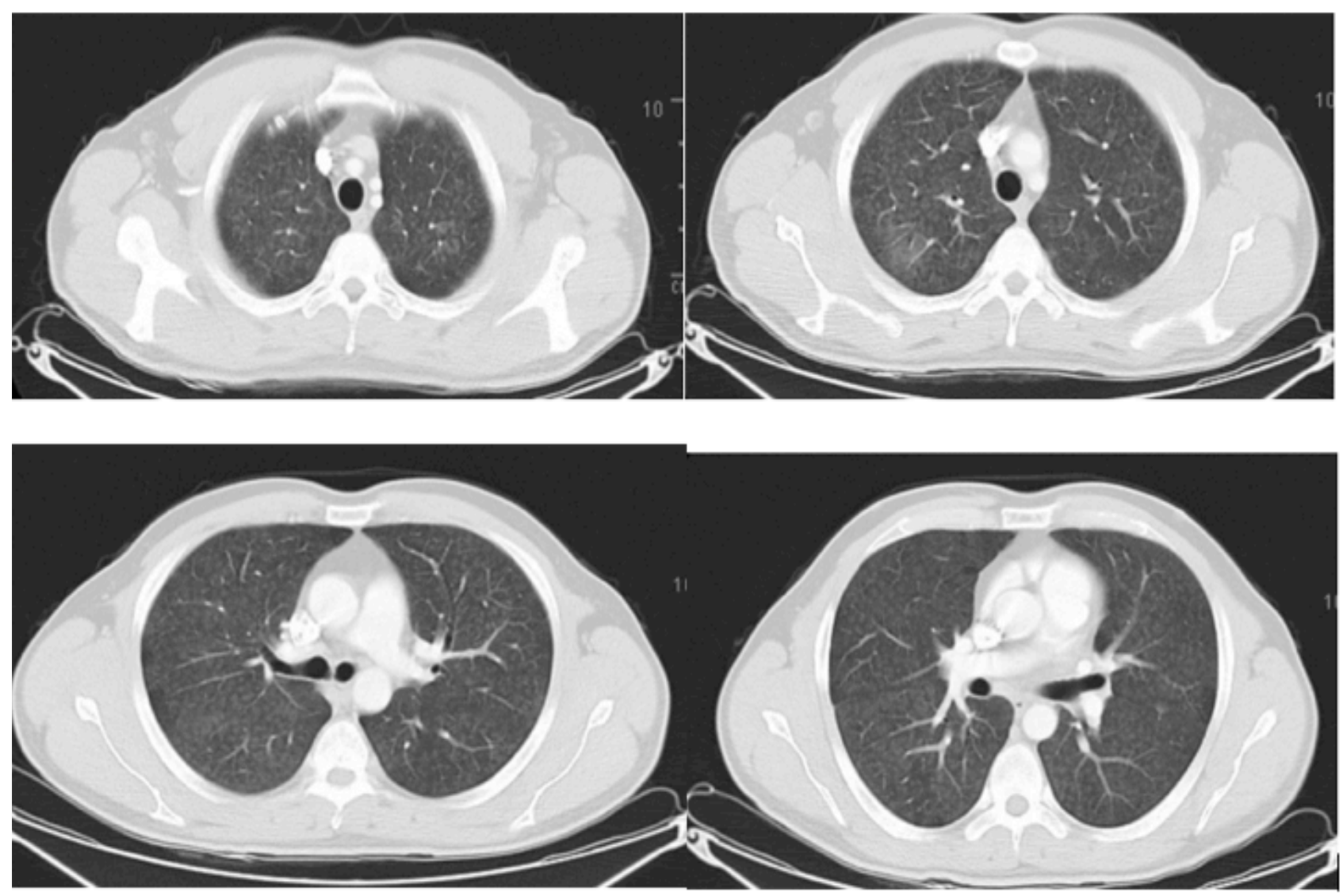

Figure 2. Computed tomography of thorax. Typical findings for subacute hypersensitivity pneumonitis such as bilateral diffuse millimetric centrilobular ground-glass nodules which are coalescing in some areas, mosaic perfusion and air trapping in basal areas were observed. 
A fiberoptic bronchoscopy was performed to evaluate upper and lower airways and obtain BAL. BAL cytology revealed percentages of lymphocytes as $85 \%$, macrophages as $10-12 \%$, and neutrophils as $2-3 \%$. Flow cytometry of BAL revealed a CD4+ to CD8+ T lymphocyte ratio of 0.41 .

Combining both detailed medical history and supporting findings of HRCT and BAL, the patient was diagnosed as subacute HP in collaboration with our hospital's multidisciplinary team for pulmonary diseases. A corticosteroid treatment with methylprednisolone (1 $\mathrm{mg}$ per $\mathrm{kg}$ ) was initiated with a tapering plan along with the recommendation of avoiding possible exposures. Symptomatic improvement was observed at his control visit one month later with this treatment.

\section{DISCUSSION}

A detailed medical history is an essential part of the evaluation a patient for differential diagnosis of HP. Important aspects of anamnesis include evaluation of occupational and environmental exposures [4]. Avian antigen is a well-known cause for HP and that form of HP is also called as bird fancier's lung or pigeon breeder's lung [5]. HP may also develop after occupational exposure to bacterial antigens in metal working fluids or low molecular weight chemicals including isocyanates and metal fumes [2], all of which may also be suspicious expositions of the patient during stainless steel cutting and welding. Thus, there was a probability of HP development related to pigeon antigens and/or other possible occupationally exposed agents in our case. Exposure history and typical HRCT findings along with lymphocyte predominant BAL cytology are accepted as sufficient for confident clinical diagnosis for HP [6]. Thus, the patient was diagnosed as HP in collaboration with our hospital's multidisciplinary team for pulmonary diseases. Removal of all possible causative agents was suggested along with corticosteroid treatment.

HP is classified as acute, subacute, and chronic according to the course of the disease [7]. Recent publications suggest to use acute/subacute HP term instead, due to vague differences between acute and subacute HP compared to chronic HP [8]. Chronic HP presents with persistent symptoms and signs due to permanent fibrotic changes in lungs. In our case, respiratory symptoms, namely dyspnea and cough, were developed gradually along with fatigue, weight loss as compatible with subacute HP. Contrary to most of the lung diseases, $80-95 \%$ of cases with HP are non-smokers, as in our case [9]. The underlying mechanism is not fully understood, but anti-inflammatory effects of nicotine may play a role [10]. In terms of lung function tests, decreased carbon monoxide diffusion is often observed in HP patients and accepted as an early and sensitive finding. But diffusion tests may also be found as normal in a small group of patients [11]. Diffusion test of our patient was normal.

In terms of HRCT, primary finding of acute HP is ground glass opacities. Most frequent findings for subacute HP include centrilobular nodules and ground glass opacities along with air trapping and mosaic perfusion. Findings of chronic HP are irregular linear opacities, honeycombing and traction bronchiectasis suggesting fibrosis $[12,13]$. In our case diffuse ground glass nodules and basal low-density areas were observed. Those findings were typical for subacute HP.

Lymphocytic predominance in BALs of subacute and chronic HP cases mainly reflects T lymphocytes with increased subgroup of CD8+ cells, thus bronchoalveolar lavage CD4+ to CD8+ Tlymphocyte ratio is decreased to less than one $[14,15]$. In our case, $85 \%$ of cells in BAL were lymphocytes and CD4+ to CD8+ T lymphocyte ratio was 0.41 . Despite lacking availability in our center, tests for precipitating antibodies in blood or BAL can prove the causative agent for the diagnosis [16]. Currently limited number of centers can analyze a few types of precipitating antibodies in Turkey. Increased availability may be achieved by establishing specialized reference centers.

In conclusion, a detailed medical history revealing environmental and occupational inhalational exposures guides the physician in the diagnosis of HP. After initial suspicion, supporting laboratory and radiologic findings confirm the diagnosis 
to provide appropriate management. Physicians should be encouraged to question their patients regarding occupational and environmental exposures. Future increase in availability of precipitating antibody tests may provide better suggestions for patients about removal of exact causative agent exposed occupationally and/or environmentally.

\section{CONFUCT OF INTEREST}

The authors declare that they have no conflict of interest. 
[1] Costabel U, Guzman J. Less common diseases: Hypersensitivity pneumonitis. Diffuse Lung Disease A Practical Approach London: Arnold. 2004: 203-12.

[2] Quirce S, Vandenplas O, Campo P, et al. Occupational hypersensitivity pneumonitis: an EAACl position paper. Allergy. 2016; 71(6): 765-79.

[3] Yildiz AN, Piskin TM, Alaguney ME, et al. Attitudes and behaviors of family physicians regarding occupational diseases. Archives of Environmental \& Occupational Health. 2019; 74(1-2): 85-92.

[4] Lacasse $Y$, Selman M, Costabel U, et al. Clinical diagnosis of hypersensitivity pneumonitis. American journal of respiratory and critical care medicine. 2003; 168(8): 952-8.

[5] Shiroshita A, Tanaka Y, Nakashima K, et al. Diagnostic accuracy of specific IgG antibodies for bird fancier's lung: a systematic review and meta-analysis. Annals of translational medicine. 2019; 7(22): 655.

[6] Vasakova M, Morell F, Walsh S, et al. Hypersensitivity Pneumonitis: Perspectives in Diagnosis and Management. Am J Respir Crit Care Med. 2017; 196(6): 680-9.

[7] Selman M, Pardo A, King TE. Hypersensitivity pneumonitis: insights in diagnosis and pathobiology. Am J Respir Crit Care Med. 2012; 186(4): 314-24.

[8] Lacasse Y, Selman M, Costabel U, et al. Classification of hy persensitivity pneumonitis: a hypothesis. International archives of allergy and immunology. 2009; 149(2): 161-6.
[9] Mohr LC. Hypersensitivity pneumonitis. Current opinion in pulmonary medicine. 2004; 10(5): 401-11.

[10] Blanchet M-R, Israël-Assayag E, Cormier Y. Inhibitory effect of nicotine on experimental hypersensitivity pneumonitis in vivo and in vitro. American journal of respiratory and critical care medicine. 2004; 169(8): 903-9.

[11] Ohtsuka Y, Munakata M, Tanimura K, et al. Smoking promotes insidious and chronic farmer's lung disease, and deteriorates the clinical outcome. Internal medicine. 1995; 34(10): 966-71.

[12] Hirschmann JV, Pipavath SN, Godwin JD. Hypersensitivity pneumonitis: a historical, clinical, and radiologic review. Radiographics. 2009; 29(7): 1921-38.

[13] Okuno K, Kobayashi K, Kotani Y, et al. A case of hard metal lung disease resembling a hypersensitive pneumonia in radiological images. Internal Medicine. 2010; 49(12): 1185-9.

[14] Girard M, Cormier Y. Hypersensitivity pneumonitis. Current opinion in allergy and clinical immunology. 2010; 10(2): 99-103.

[15] Wells A. The clinical utility of bronchoalveolar lavage in diffuse parenchymal lung disease. European respiratory review. 2010; 19(117): 237-41.

[16] Soumagne T, Dalphin JC. Current and emerging techniques for the diagnosis of hypersensitivity pneumonitis. Expert review of respiratory medicine. 2018; 12(6): 493-507. 